\title{
A Teen-Led, Volunteer-based NICU Reading Program: A Model for Supporting Family Reading and Family Integrated Care
}

Benjamin Olshin, Howard Cohen, MD

\section{Introduction:}

NICU babies are at high risk of neurodevelopmental impairment for multiple reasons, including prematurity, critical illness, and family emotional and economic stressors associated with hospitalization in the NICU. (1) Care in single-patient-room NICUs can compound the issues of sensory deprivation and contribute to speech and language deficits in NICU graduates. (2) Reading aloud with babies creates and strengthens neural connections that "promote ... social-emotional development...and language and literacy skills during this critical period of early brain and child development." (3) Providing parents and other caregivers books and encouraging them to read to their infants in the NICU is a low-cost intervention to increase infants' speech and language interactions. Parent reading with their baby in the NICU supports family integrated care and bonding (4) and improves the NICU experience.

"The NICU Reading Program is a collaboration between teen volunteers and NICU providers, consisting of four discrete components - Admit Reading Packets, One-on-one Book Rounds, a Family Shared Reading Library, and literacy events and celebrations."

Babies With Books (BWB) NICU Reading Program:

BWB, a teen-led volunteer organization, began its first NICU Reading Program at Randall Children's Hospital (RCH) in 2017. The NICU Reading Program is a collaboration between teen volunteers and NICU providers, consisting of four discrete components - Admit Reading Packets, One-on-one Book Rounds, a Family Shared Reading Library, and literacy events and celebrations. Admit Reading Packets contain a book, bookmark, and information on how and why to read aloud with babies beginning in the NICU. Teens source and assemble these admit packets, which are given by healthcare providers to each infant at NICU admission. One-on-one Book Rounds encourage and reinforce NICU reading. During book rounds, teen volunteers meet weekly

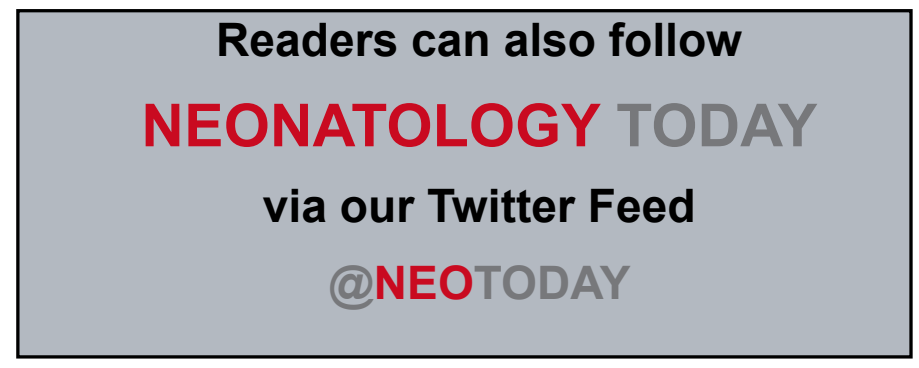

with NICU families to talk with them about how to read with their infant and why reading aloud to their babies beginning in the NICU is important. Some of this information was developed in collaboration with Reach Out And Read ${ }^{\circledR}$ (ROR). Families are offered their choice of 3 books from a mobile book cart to read with their infant, keep in the NICU, and bring home at NICU discharge. The Family Shared Reading Library is a library located outside of the NICU (ex. in the NICU lobby or lounge) stocked with donated, gently used books. Literacy Events \& Celebrations include NICU reada-thons, book nooks at NICU reunions, and other literacy promoting events that engage families in shared reading. In BWB's first NICU read-a-thon at $\mathrm{RCH}, 45 \%$ of families participated, and all surveyed staff and families expressed high satisfaction. BWB has also hosted a "book nook" program at the RCH NICU reunion, during which we provided more than 200 donated books to NICU graduates and their siblings and read stories with them. Through this NICU Reading Program, BWB has served more than 850 NICU babies at RCH.
"We recommend books by a wide range of authors that engage and represent the diversity of the NICU patient population. Funding is through generous foundation grants as well as individual and corporate donations."

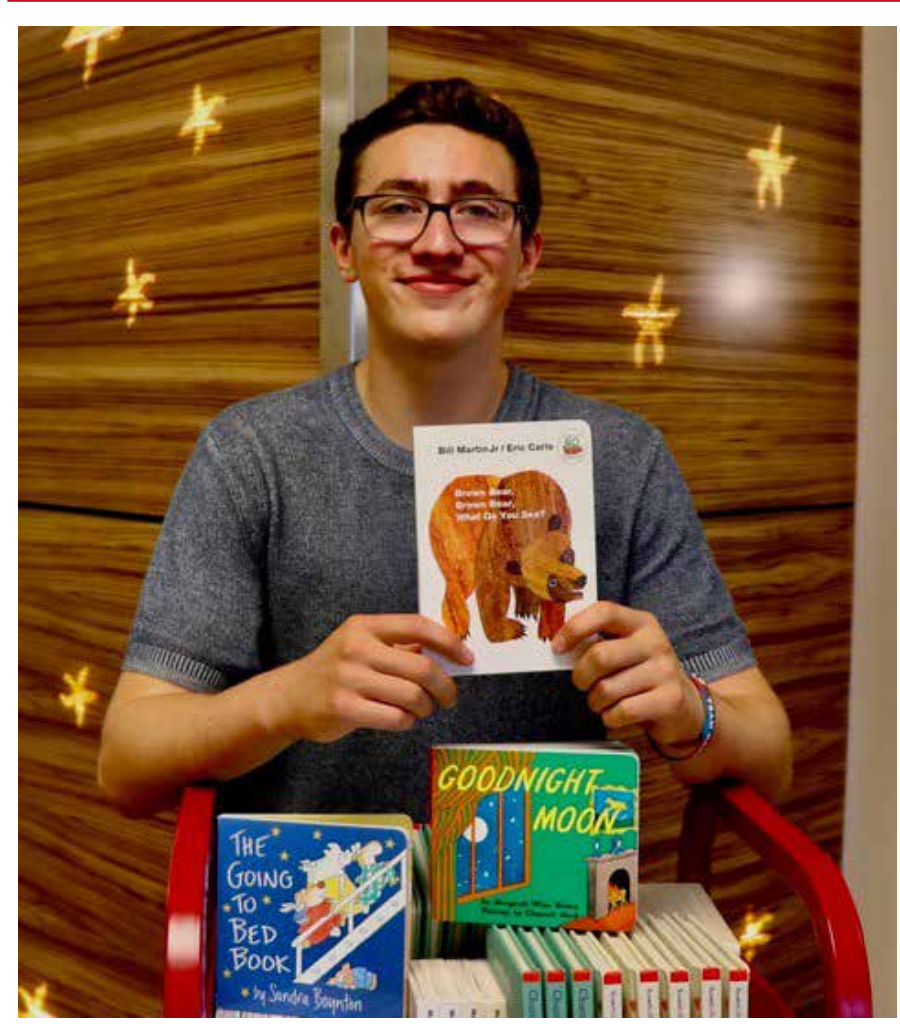


Books used in the Reading Program include a variety of high contrast board books, children's stories, and "I love you" type books. Only new books are used with babies. Donated, gently used books may be used in the Family Shared Library and in "book nooks" at NICU reunions for NICU families and graduates. Books are available in multiple languages, and picture books are available for families whose primary language is not represented and for non-reading families. We recommend books by a wide range of authors that engage and represent the diversity of the NICU patient population. Funding is through generous foundation grants as well as individual and corporate donations. We receive donated books from a local book bank and a used bookstore.

Like all hospital-based programs, BWB has been impacted by the COVID-19 pandemic. The BWB teens have continued to source and assemble admit reading packets but do so offsite and deliver these to the hospital where they are stored for at least 72 hours prior to being given to NICU families. To assemble and deliver admit packets, volunteers must be symptom-free, wear masks, and adhere to strict hand hygiene. One-on-one volunteer-led book rounds have been paused during COVID-19 but can be performed by personnel with continued access to the NICU. Shared Family Reading Libraries are not recommended during COVID-19. Reada-thons remain a great way to support infants and families and build NICU morale during COVID-19.

\section{Conclusion:}

By engaging motivated, passionate, and creative teen volunteers in our BWB Reading Program, we provide valuable service to NICU babies and families with limited burden and cost to healthcare providers and hospitals.

\section{References}

1. What Every Pediatric Professional Can Do. https://www.aap. org/en-us/literacy/Literacy/For-Professionals/What-EveryPediatric-Professional-Can-Do-To-Promote-Early-Literacyand-Early-Learning/booksbuildconnections_whateverypediatricprofessionalcando.pdf.

2. A Risk of Sensory Deprivation in the Neonatal Intensive Care Unit. Alan H. Jobe, MD, Ph.D. Published: March 24, 2014, DOI: https://doi.org/10.1016/j.jpeds.2014.01.072

3. Literacy Promotion: An Essential Component of Primary Care Pediatric Practice. Council On Early Childhood. Pediatrics Aug 2014, 134 (2) 404-409; DOI: 10.1542/peds.20141384

4. Bonding With Books: The Parent-Infant Connection in the Neonatal Intensive Care Unit. Walker, Lynne J., MSN Neonatal Network Vol 32 Issue 2, DOI: 10.1891/07300832.32.2.104

The authors have no conflicts of interests to disclose.
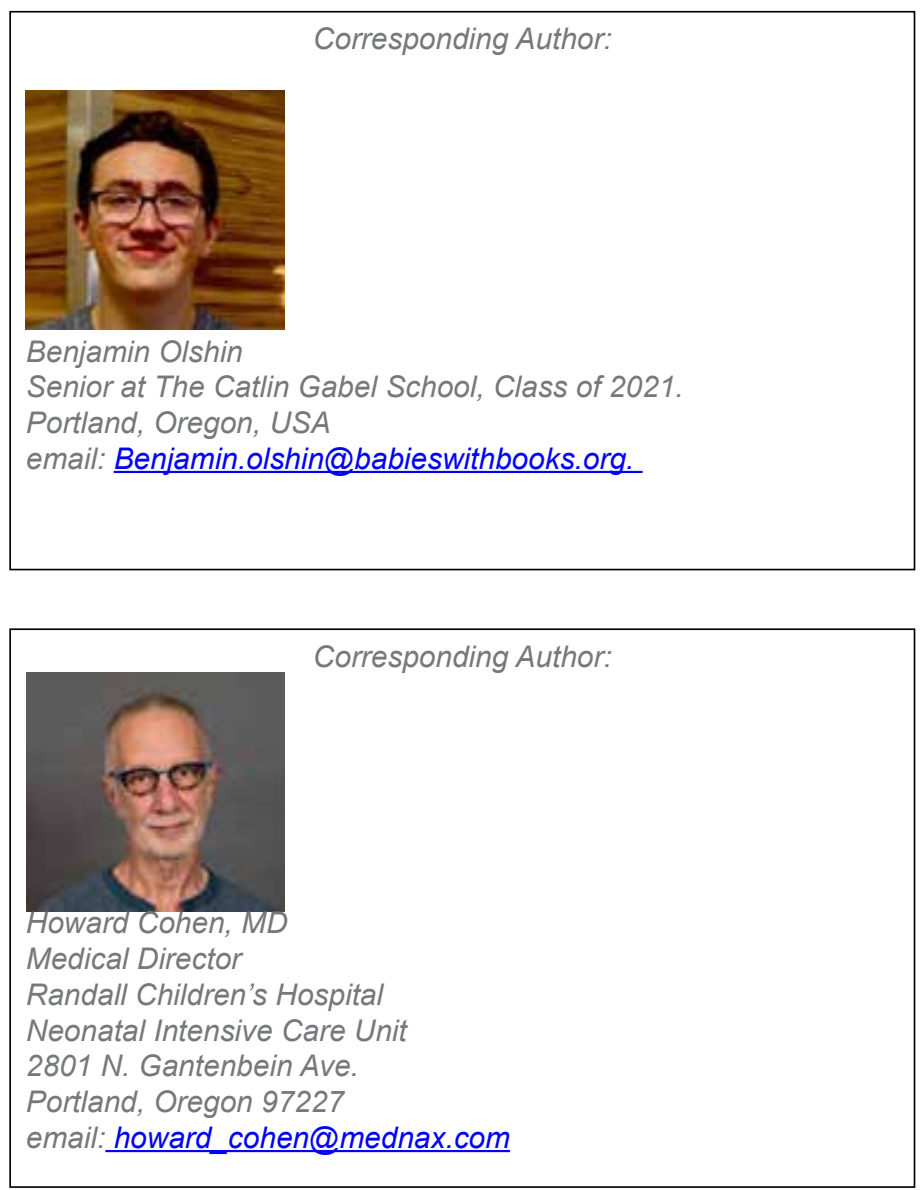

Join our multi-site NICU Read-a-thon September 14-24, 2020! This September 14-24 2020, BWB is organizing an international, multi-site NICU read-a-thon. To register for it, please complete this short form: https://forms.gle/YgrzafVi2yYpwPeZ6. By registering, our team will also provide you with information on how to organize and implement a read-a-thon including downloadable family and healthcare provider information sheets, reading tracking sheets/raffle tickets, bookmarks, prize suggestions, and more! We have also created a NICU Reading Program process guide to help you start or expand your NICU Reading Program. Request the guide here: https:// forms.gle/wj6uYXfyKZydXQZw5. Visit us at babieswithbooks. org and email us at babieswithbooks@gmail.com.

NEONATOLOGY TODAY is interested in publishing manuscripts from Neonatologists, Fellows, NNPs and those involved in caring for neonates on case studies, research results, hospital news, meeting announcements, and other pertinent topics.

Please submit your manuscript to: LomaLindaPublishingCompany@gmail.com 